\title{
Numerical Simulation of Airliner Cabin Environment based on Various Inlet Angles
}

\author{
Zhuo Huan Hu ${ }^{1}$, Lu Lu Wang ${ }^{1, *}$ Yang Lu ${ }^{2}$ and Mo Yang ${ }^{1}$ \\ ${ }^{1}$ School of Energy and Power Engineering, University of Shanghai for Science and Technology, Shanghai, 200093 - China \\ ${ }^{2}$ Faculty of Engineering, Computer \& Mathematical Sciences, The University of Adelaide, Adelaide, SA 5005 - Australia
}

Received 15 January 2014; Accepted 20 July 2014

\begin{abstract}
The study of airflow transport in airliner cabins is extremely important in creating a comfortable environment. The air temperature field and velocity field in the airliner cabin have significant influence on the health of pilots and passengers. In this study, heat transfer based on numerical study was carried out to investigate the effects of natural convection and air distribution with different angles. The average Reynolds equation and low Reynolds number turbulence model were used to simulate the airflow in the cabin. The convective term of convection diffusion equation was implemented with higher-order accurate schemes. Mathematical statistics was adopted to process the final data. Results showed that the effect of the natural convection could be negligible. Additional studies presented that air temperature field and flow field were largely affected by various inlet angles. A set of optimum matching inlet vane angles that could create a comfortable environment was determined.
\end{abstract}

Keywords: Airliner Cabin, Numerical Simulation, Heat Transfer

\section{Introduction}

The development of science and technology has brought about higher demands in flight technology and flight comfort. Ensuring the proper operation of the aircraft with energy-saving principles and satisfying the needs of pilots and passengers in terms of comfort have become challenges in aircraft design. Increasing the comfort of pilots and passengers during a flight, strengthening energy saving, and guaranteeing flight safety are important considerations in aircraft design [1], [2], [3]. The main environment parameters in the airliner cabin are temperature, pressure, pressure gradient, excess pressure, humidity, and cleanliness of cabin air. The regulation of smoothness and comfort in the internal environment of the cabin are related to inlet temperature, velocity, angle, and position. Comfortable cabin environment would be achieved with reasonable importation of conditions.

Previous results of heat and mass transfer research have been derived based on numerical simulation of internal fluid flow of a large passenger airliner cabin. Johannes and Julien et al. [4], [5], [6], [7] combined numerical simulation with the experiment on particle image velocimetry. This study demonstrated that the low Reynolds number turbulence model fit the actual situation more precisely than other models in relation to the simulation of isothermalairliner cabin flow. Zhang and Ang [8] simulated the airflow field and temperature field of the two-dimensional cabin model. The simulation results showed that the convection terms of equations treated by the higher-order scheme is more accurate and reasonable compared with those treated by the lower-order scheme. Stephane et al. [9] combined numerical

\footnotetext{
*E-mail address: huzhuohuan@hotmail.com

ISSN: 1791-2377 @ 2014 Kavala Institute of Technology. All rights reserved.
}

and experimental simulations by using the particle imaged velocimetry, which achieved the velocity field in a large passenger airliner cabin. Yan et al. [10] studied the unsteady airborne pollutant transport mechanism within an airliner cabin mock-up using the numerical simulation and experiment method without considering the heat source. Nevertheless, the numerical results were in conformity with the experimental results. Aakash et al. [11], [12], [13] established the two-dimension or three-dimension simulation model of the airliner cabin and investigated the flow field of a large passenger airliner cabin from the mass transfer perspective. Literature [13] reveals the numerous initiatives to study the law of internal pollutants nonlinear diffusion. However, all these studies did not consider the heat transfer problems.

On the other side of the research spectrum, the effects of moving human bodies on the flow and contaminant Received transport inside an airliner cabin was investigated by Stephane et al. [14], [15], [16], [17]. The flow field and contaminant transport were measured by the particle image velocimetry (PIV) and planar laser-induced fluorescence techniques. The experimental data obtained were used to validate the computational fluid dynamic (CFD) model. The results demonstrated that the CFD model can effectively capture the characteristic flow features and contaminant transport observed in the small-scale model. Liu et al. [18], [19] conducted experimental measurements and numerical simulations of air distributions in airliner cabins. The CFD models provided a means to study the concentration and deposition profiles at high spatial and temporal resolutions in airliner cabin environments. Sastry et al. [20] developed a new CFD mode for studying pesticide concentrations and depositions following the spraying of a portion of an airliner cabin. This model was evaluated against the data from spraying experiments conducted in a cabin mockup. 
In conclusion, the study of airliner cabin based on heat and mass transfer not only contributes to flight safety, but also to the improvement of the efficiency of equipment. The engineering context of this paper is composed of the thermal environment of the double-service aircraft that carries passengers and goods. It focuses on interior heat source and mixture air flow in the cabin. These aspects were typically ignored in the previous studies. The actual processes of flight can be divided into three stages, take-off and climbing, cruise and landing, and maintaining the cabin environment. The third stage is the most difficult task because this is not an independent stage, but a component of the take-off stage and landing stages. The temperature field and flow field in the airliner cabin during the landing process are analyzed in this study, a process in which FLUENT was adopted.

\section{Mathematical Models}

\subsection{Turbulence Models}

The actual working condition of the heat and mass transfer in the airliner cabin is extremely complex. Thus, the heat and mass transfer models should be simplified to obtain the mathematical models of gas state space in the cabin. This study assumes the following:

(1) The working medium is incompressible fluid.

(2) Turbulent flow is steady.

(3) Thermal radiation among solid walls in the cabin can be ignored.

(4) The airflow is an incompressible flow at low speed. Moreover, heat dissipation caused by the viscous force can be ignored.

Air flow rate in the cabin is extremely low. Moreover, the viscosity of turbulence near the wall is slight. The airflow in the airliner cabin studied and adopted belongs to Launder-Sharma low Reynolds number flow and $k-\varepsilon$ turbulence model [21], [22], [23], [24], [25].

\subsection{Governing Equations}

Navier-Stokes equations were used to simulate the airflow. In the Cartesian coordinate system, three-dimensional Navier-Stokes equations [26], [27] in tensor forms were used to solve the problems of steady state and incompressible turbulent. These equations are as follows:

Continuity equation:

$$
\frac{\partial \rho}{\partial t}+\frac{\partial}{\partial x_{j}}\left(\rho u_{j}\right)=0
$$

Momentum equation:

$$
\begin{aligned}
& \frac{\partial\left(\rho u_{i}\right)}{\partial t}+\frac{\partial\left(\rho u_{i} u_{j}\right)}{\partial x_{j}}=-\frac{\partial p}{\partial x_{i}}+ \\
& \frac{\partial}{\partial x_{j}}\left[\mu\left(\frac{\partial u_{i}}{\partial x_{j}}+\frac{\partial u_{j}}{\partial x_{i}}-\frac{2}{3} \delta_{i j} \frac{\partial u_{k}}{\partial x_{k}}\right)-\rho \overline{u_{i}^{\prime} u_{j}^{\prime}}\right]
\end{aligned}
$$

Energy equation:

$$
\frac{\partial(\rho T)}{\partial t}+\frac{\partial\left(\rho u_{j} T\right)}{\partial x_{j}}=\frac{\partial}{\partial x_{j}}\left(\frac{\mu}{\operatorname{Pr}} \frac{\partial T}{\partial x_{j}}-\rho \overline{u_{j}^{\prime} T^{\prime}}\right)+S_{T}
$$

Low Reynolds number turbulence $k-\varepsilon$ models were used. Turbulent kinetic energy $\mathrm{k}$ equation and dissipation rate $\varepsilon$ equation in $k-\varepsilon$ model are as follows:

$$
\begin{aligned}
& \rho \frac{d k}{d t}=\frac{\partial}{\partial x_{j}}\left[\left(\mu+\frac{\mu_{l}}{\sigma_{k}}\right) \frac{\partial k}{\partial x_{j}}\right]+G_{k}+G_{b}-\rho \varepsilon-Y_{M} \\
& \rho \frac{d \varepsilon}{d t}=\frac{\partial}{\partial x_{j}}\left[\left(\mu+\frac{\mu_{l}}{\sigma_{\varepsilon}}\right) \frac{\partial \varepsilon}{\partial x_{j}}\right]+\frac{C_{1 \varepsilon} \varepsilon}{k}\left(G_{k}+C_{3 \varepsilon} G_{b}\right)-C_{2 \varepsilon} \rho \frac{\varepsilon^{2}}{k}
\end{aligned}
$$

Where $G_{k}$ refers to the turbulent kinetic energy caused by the average flow velocity gradient, $G_{b}$ refers to the turbulent kinetic energy caused by buoyancy, and $Y_{M}$ refers to the effect of compressible turbulent flow pulsation expansion on the total dissipation rate. Viscosities of the turbulence coefficient are $\mu_{l}=\rho C_{u} \frac{k^{2}}{\varepsilon}, C_{1 \varepsilon}=1.44, C_{2 \varepsilon}=1.92$, and $C_{3 \varepsilon}=0.09$.

\section{Numerical Analysis}

The temperature field and velocity field of airflow in the passenger and cargo transport airliner cabin were analyzed.

\subsection{Boundary Conditions}

The air inlet is based on boundary conditions, which assume an air inlet speed of $4 \mathrm{~m} / \mathrm{s}$ and an inlet temperature of $20^{\circ} \mathrm{C}$. This model sets two air inlets. The first inlet is set as the reference point. Figure 1 shows the following air inlet angles of the different air inlets: $a=30^{\circ}, b=45^{\circ}, c=60^{\circ}, d=75^{\circ}$, $\mathrm{e}=90^{\circ}, \mathrm{f}=105^{\circ}, \mathrm{g}=120^{\circ}, \mathrm{h}=135^{\circ}, \mathrm{i}=150^{\circ}$.

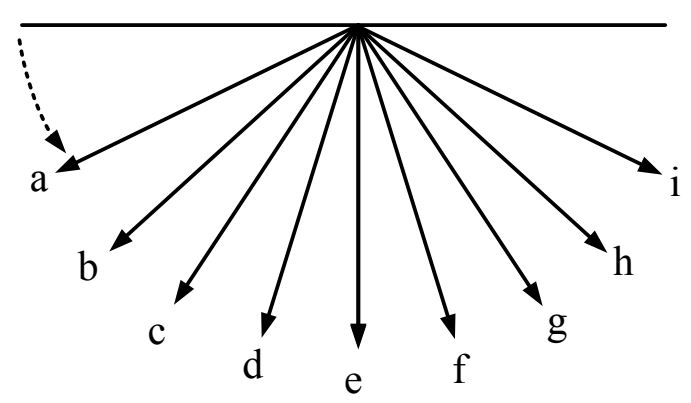

Fig. 1. Various inlet angles

The solid walls of the cabin are all set in the non-slip condition. The velocity can be ignored. In this model, the internal walls in the airliner cabin dissipate heat outward. The human body and tank engine are regarded as sources of the heat release. The front and back boundaries are set as adiabatic surfaces. This conduct of the simulation is assumed to be implemented in the middle period of the flight.

Remark 1. The air speed of the air outlet was amended based on the law of mass conservation.

\subsection{Simulation Results}

The Grashof number was controlled by changing the gravity acceleration. Final data were analyzed by the mathematical statistics method. Table 1 shows the temperature fluctuations in the designated area of the cabin under different Grashof 
numbers. The fluctuations indicate negligible variance of temperature in the cabin under different conditions. Figure 2 shows the temperature distribution in the cabin with different distances from the center of the cabin and temperature fluctuations between $291.4 \mathrm{~K}$ to $292.4 \mathrm{~K}$. Data analysis in Table 1 and Figure 2 reveals the extremely slight and negligible influence of natural convection. Figure 3 shows the velocity field of the vertical section under different inlet angles. Figure 4 presents the velocity field of the horizontal section under different inlet angles. Figure 5 shows the velocity variance of the center section under different inlet angles. Figures 3, 4, and 5 show the relatively obvious influence of inlet angle on the flow field in the cabin.

Tab. 1. Variance of temperature in different Grashof numbers

\begin{tabular}{c|c|c|c|c|c}
$\mathbf{g}\left(\mathbf{m} / \mathbf{s}^{\mathbf{2}}\right)$ & 0.00098 & 0.0098 & 0.098 & 0.98 & 9.8 \\
\hline $\mathbf{s}$ & 0.867 & 0.868 & 1.155 & 1.214 & 1.038
\end{tabular}

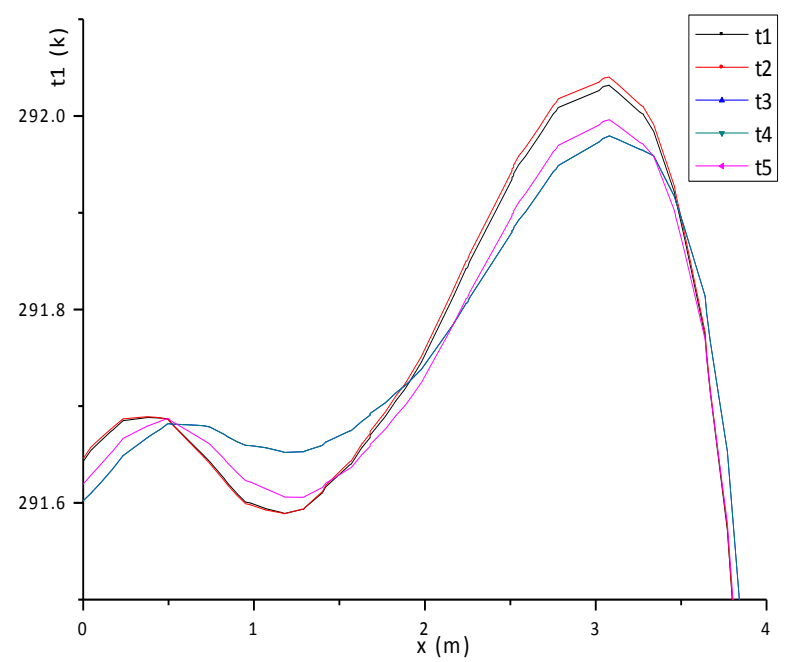

Fig. 2. Temperature distribution with different distances from the center of the cabin
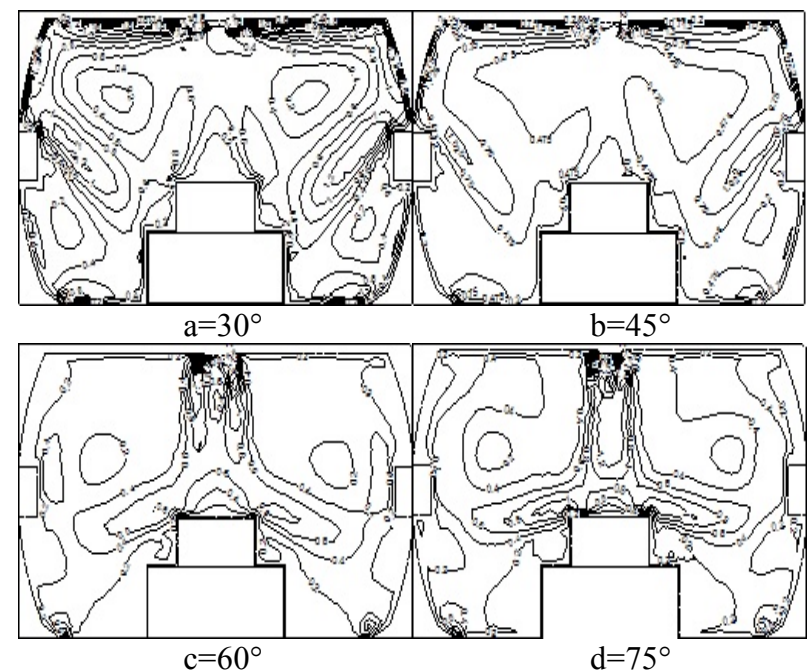
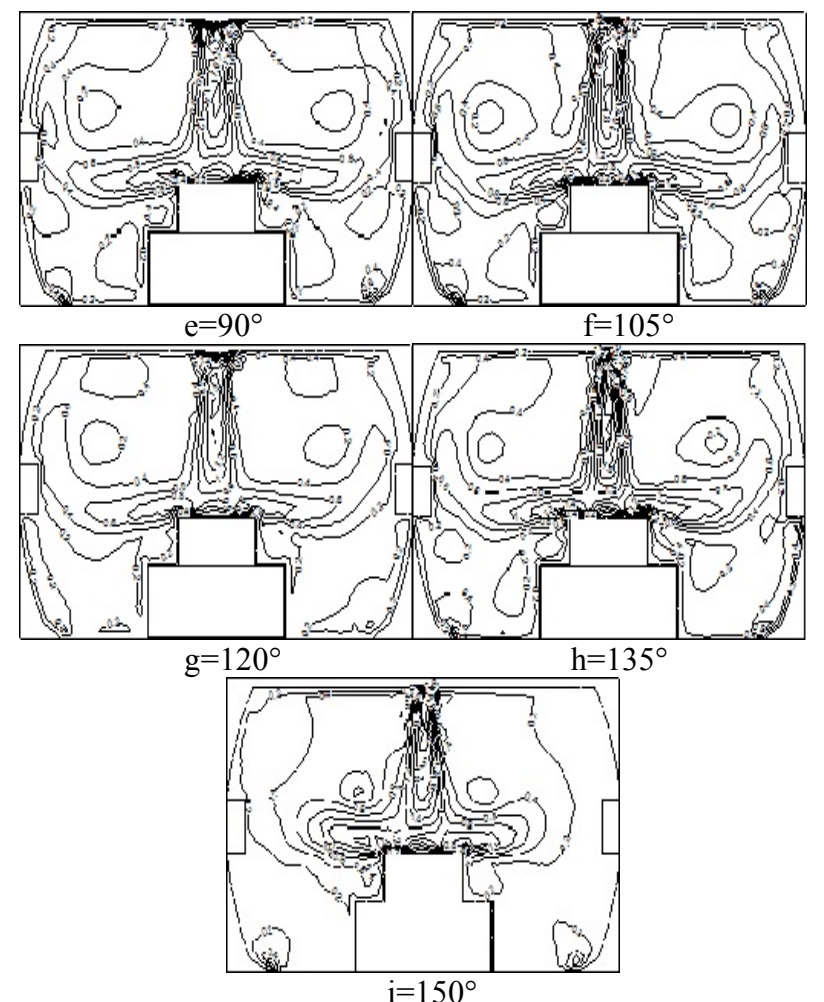

Fig. 3. Flow field of the center longitudinal section in different air inlet angles

Figure 3 shows that several swirls are generated in the cabin, which can result in a more balanced distribution of the flow field. However, these swirls negatively influence the renewal of air in terms of mass transfer. In addition, the increase of air inlet angle results in a higher velocity gradient near the wall in the small angles, as well as a higher velocity gradient near the center in large angles. With the exception of the air inlet, the velocity gradient of most parts of the cabin is lower than $1 \mathrm{~m} / \mathrm{s}$. This gradient is within the scope of comfort for pilots and passengers. Similar laws are applicable to Figures 3 and 4.

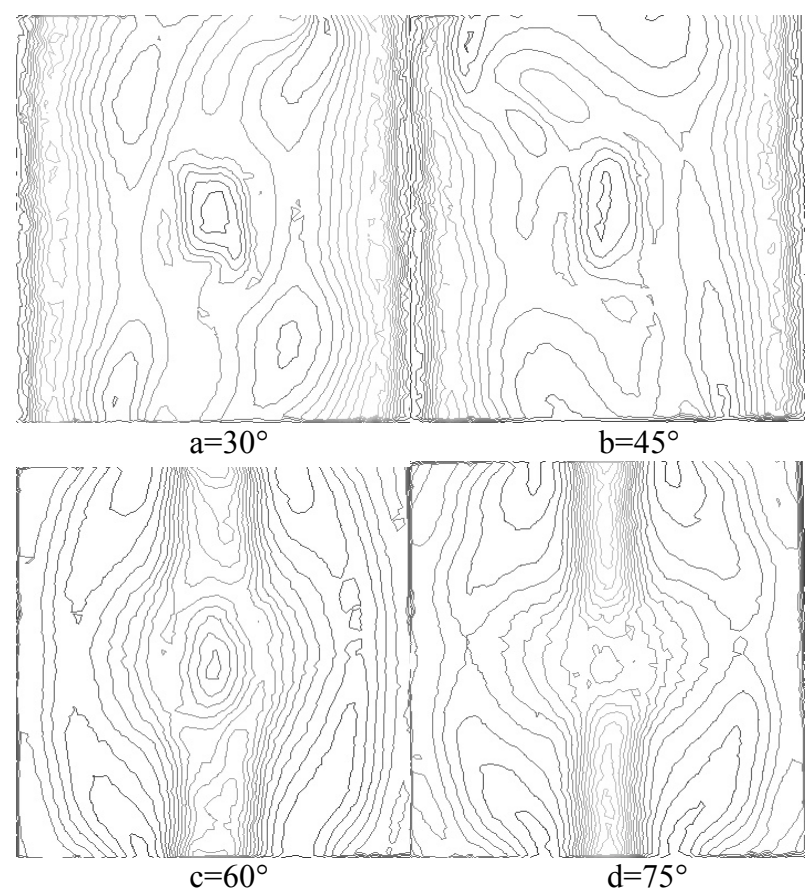




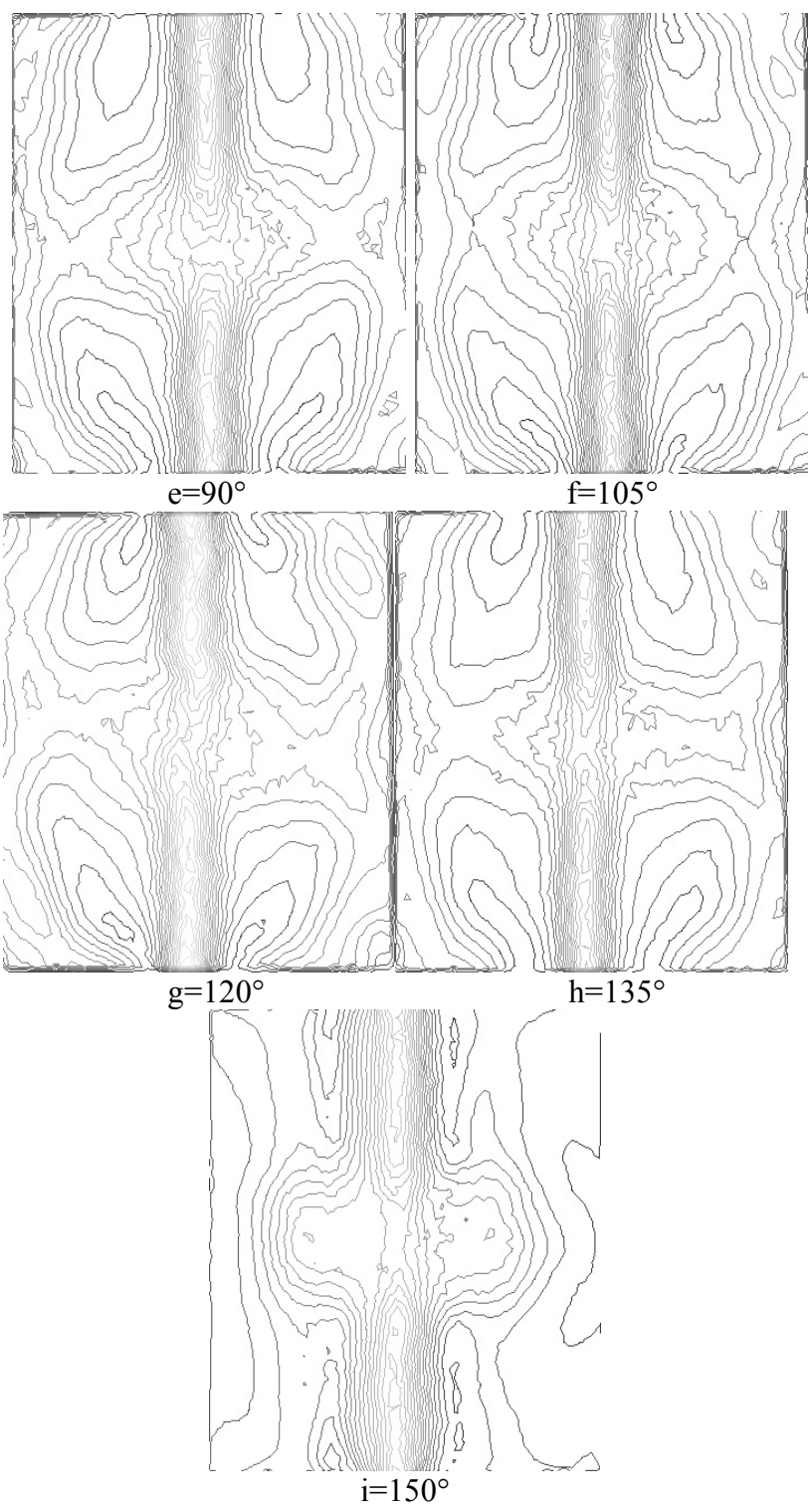

Fig. 4. Flow field of the center cross section in different air inlet angles

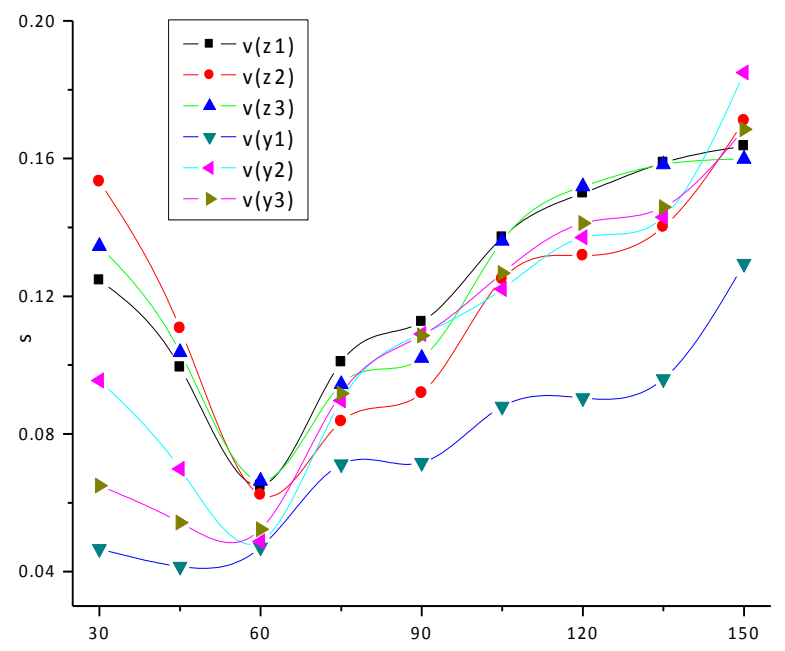

Fig. 5. Variance of velocity in different sections according to the air inlet angles

Figure 5 shows that velocity variances have noticeable changes in different angles and similar changing laws in each section. In addition, the order of magnitude of the overall variance is slight. Smaller variance around the angle $60^{\circ}$ is determined. Hence, the flow field is more distributed compared with those of other angles around the inlet.

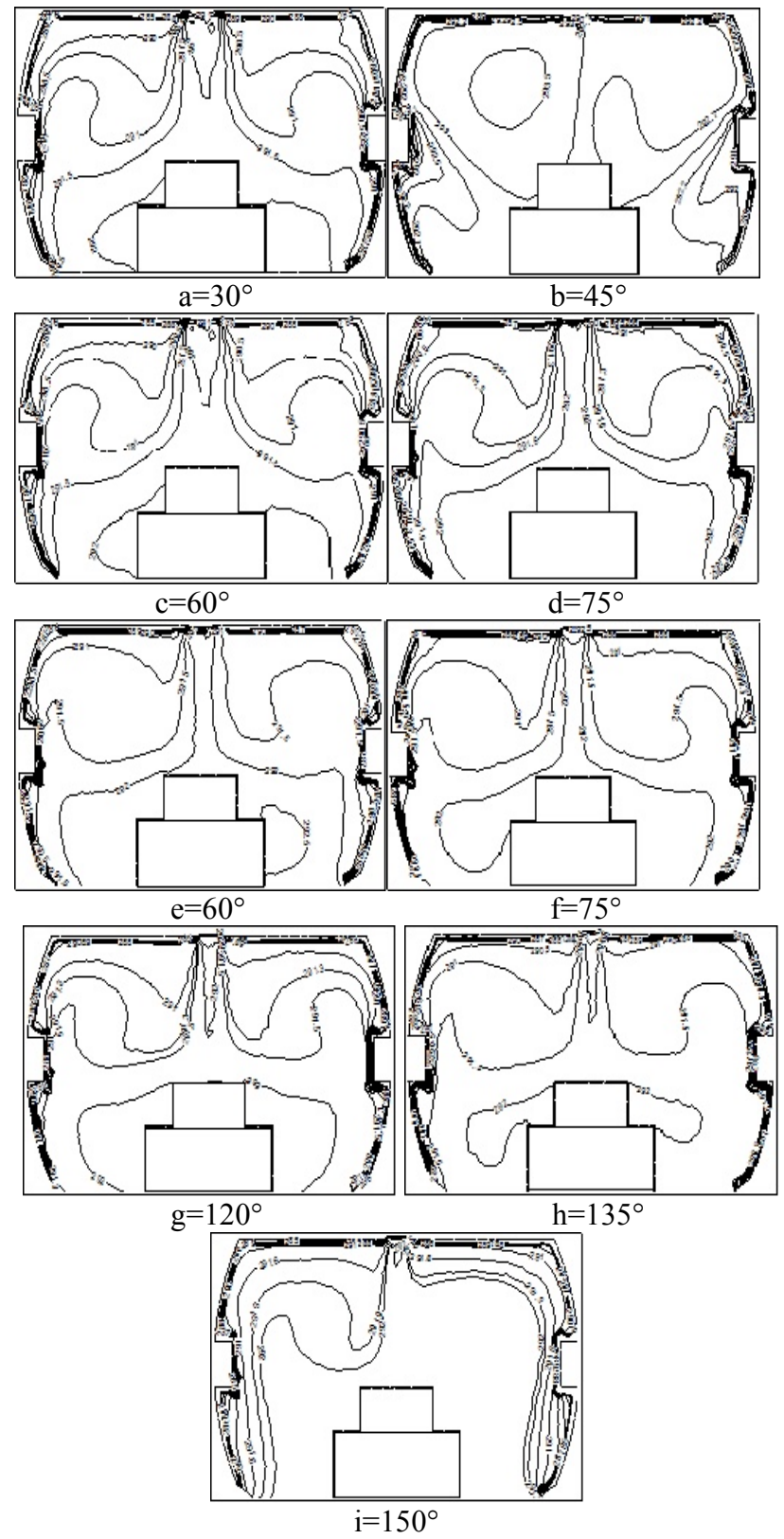

Fig. 6. Temperature field of the center longitudinal section in the different air inlet angles

Figure 6 shows that the temperature gradient is larger near the wall because of the outward heat loss of the wall. Moreover, the temperature tends to be uniform when going slightly farther from the wall. The air flow on the wall will enhance the heat preservation effect of the wall in the case of the small inlet angles. Therefore, the expansion of the angles weakens the heat preservation effect, reduces the surface temperature of the wall, and increases the difference between the wall surface temperature and temperature of the middle area. 


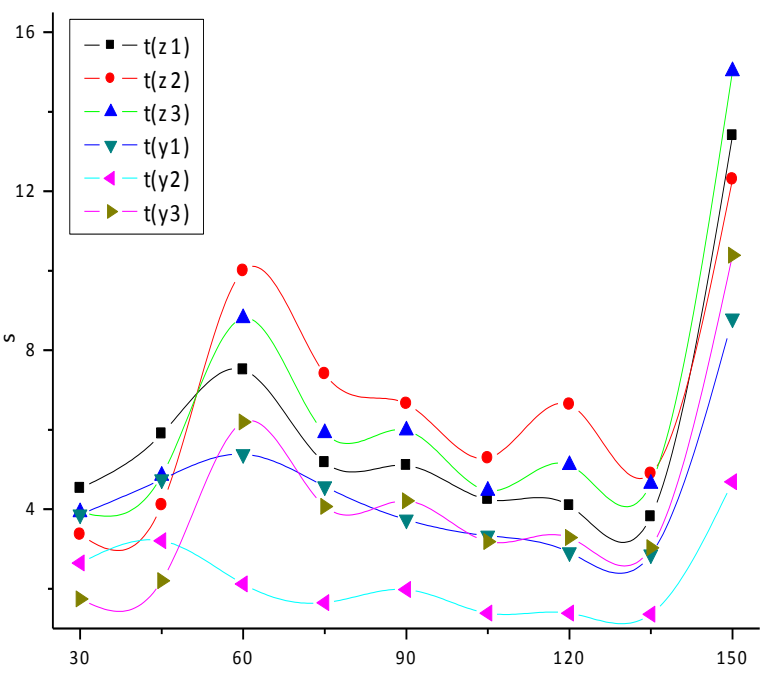

Fig. 7. Variance of temperature in different sections according to the air inlet angles

Less confluence in the two inlet airflows is found when the angle is less than $90^{\circ}$. The increase in the angle to more than $90^{\circ}$ results in earlier and more balanced confluence of the two airflows. Thus, with the increase of inlet angle, temperature variance tends to decrease (Figure 7). However, the wall surface temperature is lower in the large inlet angle. The difference between the wall surface temperature and surface temperature of the pilots and passengers is greater in this angle. Moreover, stronger thermal radiation effect is formed between these temperatures in this angle.

\section{Conclusions}

The average Reynolds equation and low Reynolds number turbulence model were used to simulate the cabin airflow. The influence of forced convection and natural convection on the temperature field in the cabin were analyzed. In addition, the convective term of the convection diffusion equation was implemented with higher-order accurate schemes. The method of mathematical statistics was adopted to process the given data.

Comfortable cabin environment will be achieved when the relevant conditions are within a reasonable range. Table 1 and Figure 2 prove that the influence of natural convection caused by the control of the Grashof number, which changes according to gravity acceleration, is minimal and can be ignored. Figures 3, 4, and 5 show that the air inlet angles of the combination passenger and freighter aircraft have greater effect on cabin flow field. Moreover, the flow field fluctuation rhythmics of longitudinal section and cross section from various angles are similar. Consequently, the airliner cabin has a more balanced flow field with the air inlet angle at the vicinity of point $60^{\circ}$. Furthermore, Figures 6 and 7 present the evident effects on cabin temperature field from various angles. The angles in the region between $35^{\circ}$ and $45^{\circ}$ are optimum.

This study determined that both temperature change and speed of the flow field can influence the coziness level of the environment. However, the change of the temperature field in the environment is more observable compared with that of the speed field. Therefore, the temperature field effect on environment deserves further attention.

\section{Acknowledgment}

This work is supported by the National Natural Science Foundation of China (Grant No. 51129602 and Grant No. 51076105).

\section{References}

1. Alivin, E., "Fundamentals of aircraft environmental control", Hayden Book Company, New York, 1968.

2. Chen, X., Yuan, X.-G., "General human-machine-environment system", Beijing University of Aeronautics and Astronautics Press, Beijing, 2000.

3. Shou, R.-Z., He, H.-S., "Aircraft's environment control”, Beijing University of Aeronautics and Astronautics Press, Beijing, 2004.

4. Bosbach, J., Pennecot, J., Wagner, C., Raffel, M., Lerche, T., Repp, S. , "Experimental and numerical simulations of turbulent ventilation in aircraft cabins", Energy 31(5), 2006, pp. 694-705.

5. Fišer, J., Jícha, M., "Impact of air distribution system on quality of ventilation in small aircraft cabin", Building and Environment 69, 2013, pp. 171-182.

6. Kühn, M., Bosbach, J., Wagner, C., "Experimental parametric study of forced and mixed convection in a passenger aircraft cabin mockup", Building and Environment 44(5), 2009, pp. 961-970.

7. Dygert, R. K., Dang, T. Q., "Experimental validation of local exhaust strategies for improved IAQ in aircraft cabins", Building and Environment 47, 2012, pp. 76-88.

8. Ang, H.-S., Zhang, D.- A., "Numerical simulation of air distribution in an aircraft cabin", Journal of Nanjing University of Aeronautics \& Astronautics 34(5), 2002, pp. 484-487.

9. Poussou, S. B., Mazumdar, S., Plesniak, M. W., Sojka, P. E., Chen, Q., "Flow and contaminant transport in an airliner cabin induced by a moving body: model experiments and CFD predictions", Atmospheric Environment 44(24), 2010, pp. 2830-2839.

10. Yan, W., Zhang, Y.-H., Sun, Y.-G., Li, D., "Experimental and CFD study of unsteady airborne pollutant transport within an aircraft cabin mock-up", Building and Environment 44(1), 2009, pp. 34-43.
11. Baker, A. J., Ericson, S. C., Orzechowski, J. A., Wong, K. L., Garner, R. P., "Aircraft passenger cabin ECS-generated ventilation velocity and mass transport CFD simulation: velocity field validation", Journal of the IEST 49(2), 2006, pp. 51-83.

12. Zhang, Z., Chen, X., Mazumdar, S., Zhang, T., Chen, Q., "Experimental and numerical investigation of airflow and contaminant transport in an airliner cabin mockup", Building and Environment 44(1), 2009, pp. 85-94.

13. Rai, A. C., Chen, Q.-Y., "Simulations of ozone distributions in an aircraft cabin using computational fluid dynamics", Atmospheric Environment 54, 2012, pp. 348-357.

14. Mazumdar, S., Poussou, S. B., Lin, C. H., Isukapalli, S. S., Plesniak, M. W., Chen, Q., "Impact of scaling and body movement on contaminant transport in airliner cabins", Atmospheric Environment 45(33), 2011, pp. 6019-6028.

15. Brohus, H., Balling, K. D., Jeppesen, D., "Influence of movements on contaminant transport in an operating room", Indoor air 16(5), 2006, pp. 356-372.

16. Matsumoto, H., Ohba, Y., "The influence of a moving object on air distribution in displacement ventilated rooms", Journal of Asian Architecture and Building Engineering 3(1), 2004, pp. 71-75.

17. Bjørn, E., Nielsen, P. V., "Dispersal of exhaled air and personal exposure in displacement ventilated rooms", Indoor air 12(3), 2002, pp. 147-164.

18. Liu, W., Mazumdar, S., Zhang, Z., Poussou, S. B., Liu, J., Lin, C. H., Chen, Q., "State-of-the-art methods for studying air distributions in commercial airliner cabins", Building and Environment 47, 2012, pp. 5-12.

19. Liu, W., Wen, J., Lin, C. H., Liu, J., Long, Z., Chen, Q., "Evaluation of various categories of turbulence models for predicting air distribution in an airliner cabin", Building and Environment 65, 2013, pp. 118-131. 
20. Isukapalli, S. S., Mazumdar, S., George, P., Wei, B., Jones, B., Weisel, C. P., "Computational fluid dynamics modeling of transport and deposition of pesticides in an aircraft cabin", Atmospheric Environment 68, 2013, pp. 198-207.

21. Yakhot, V., Orszag, S. A., "Renormalization-group analysis of turbulence", Physical Review Letters 57(14), 1986, pp. 3-51.

22. Chen Q., "Comparison of different $k-\varepsilon$ models for indoor air flow computations", Numerical Heat Transfer 28, 1995, pp. 353369 .

23. Günther, G., Bosbach, J., Pennecot, J., Wagner, C., Lerche, T., Gores, I., "Experimental and numerical simulations of idealized aircraft cabin flows", Aerospace Science and Technology 10(7), 2006, pp. 563-573.
24. Zhai, Z.-J., Zhang, Z., Zhang, W., \& Chen, Q.-Y., "Evaluation of various turbulence models in predicting airflow and turbulence in enclosed environments by CFD: Part 1 -Summary of prevalent turbulence models", Hvac\&R Research 13(6), 2007, pp. 853-870.

25. Zhang, Z., Zhang, W., Zhai, Z.-J., Chen, Q.-Y., "Evaluation of various turbulence models in predicting airflow and turbulence in enclosed environments by CFD: Part 2-Comparison with experimental data from literature", Hvac\&R Research 13(6), 2007, pp. 871-886.

26. Shen, H.-F., Yuan, X.-G., "Numerical Simulation and Experiment on Air Flow and Heat Transfer in Fighter Plane Cockpit." Acta Aeronautica Et Astronautica Sinica 30(1), 2009, pp. 30-39.

27. Jiang, F., Huang, P., "Advanced application and example analysis of FLUENT", Tsinghua University Press, Beijing, 2008 